\section{O trabalho docente de uma professora supervisora do PIBID - Língua Portuguesa na perspectiva dos licenciandos}

The teaching work of a professor supervisor of pibid portuguese language from the perspective of licenses

\section{Andreia Rezende Garcia-Reis (iD) 9}

andreiargarcia@yahoo.com.br

Universidade Federal de Juiz de Fora - UFJF

\section{Giovana Rabite Callian (ID) 9}

giovana_callian@hotmail.com

Universidade Federal de Juiz de Fora - UFJF

\section{Resumo}

O objetivo deste artigo é investigar se quatro dimensões de trabalho, das oito propostas por Machado (2007), estão presentes no trabalho docente da supervisora do Pibid - Letras/Licenciatura - da Universidade Federal de Juiz de Fora (UFJF). Utilizamos, nesta pesquisa, aportes teórico-metodológicos do Interacionismo Sociodiscursivo (ISD) (BRONCKART, 1999, 2006, 2008; MACHADO, 2007, 2009), assumindo a linguagem como atividade central do desenvolvimento humano, uma vez que é por meio dela que interagimos socialmente através dos discursos que produzimos. Os dados tomados para análise emergem de entrevistas semiestruturadas com os alunos egressos do Pibid - Língua Portuguesa. Como metodologia de análise, utilizamos o procedimento proposto por Bronckart (2008) e Bulea (2010), no qual as entrevistas são divididas em duas categorias decorrentes da distribuição dos turnos de fala: Segmentos de Orientação Temática (SOT) e Segmentos de Tratamento Temático (STT). As entrevistas revelaram que as quatro dimensões de trabalho estão presentes significativamente no trabalho docente da professora supervisora do Pibid.

Palavras-chave

Interacionismo Sociodiscursivo. Trabalho docente. Formação docente. Pibid.

\section{Abstract}

The objective of this article is to investigate if four the working dimensions, of this eight proposed by Machado (2007), are present in the teaching work of the supervisor of Pibid - Letras/Licenciatura - in the Federal University of Juiz de Fora (UFJF). We used, in this research, theoretical-methodological contributions of Sociodiscursive Interactionism - ISD - (BRONCKART, 1999, 2006, 2008; MACHADO, 2007, 2009), assuming the language as the central activity of human development, since it is through it that we interact socially through the discourses we produce. The data taken for analysis emerge from semi-structured interviews with former students of Pibid - Portuguese Language. As analysis methodology, we use the procedure proposed by Bronckart (2008) and Bulea (2010), in which the interviews are divided into two

\section{Linguagęm Foco}

Revista do Programa de Pós-Graduação em Linguística Aplicada da UECE

FLUXO DA SUBMISSÃO

Submissão do trabalho: $24 / 02 / 2021$ Aprovação do trabalho: 04/05/2021 Publicação do trabalho: 04/06/2021

\section{COMO CITAR}

GARCIA-REIS, Andreia Rezende; CALLIAN, Giovana Rabite. O trabalho docente de uma professora supervisora do PIBID - Língua Portuguesa na perspectiva dos licenciandos. Revista Linguagem em Foco, v.13, n.1, 2021. p. 139-161. Disponível em: https://revistas.uece.br/ index.php/linguagememfoco/article/view/4915.

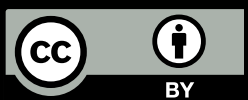

Verificado com

\title{
Plagius
}


categories resulting from the distribution of the speech turns: Segments of Thematic Orientation (SOT) and Segments of Thematic Treatment (STT). The interviews revealed that the four dimensions of work are significantly present in the teaching work of the Pibid supervising teacher.

Keywords

Sociodiscursive Interactionism. Teaching work. Teacher training. Pibid.

\section{Introdução}

O campo educacional sempre foi objeto de estudo de diversas pesquisas, no entanto, as questões referentes ao trabalho docente nem sempre eram consideradas. As pesquisas relacionadas a essa temática são bem recentes no campo do Interacionismo Sociodiscursivo e autores como Bronckart (1999, 2006, 2008), Bueno (2007) e Machado $(2007,2009)$ têm direcionado um olhar mais atento sobre as questões que envolvem o trabalho do professor nos últimos anos.

Consoante Machado (2002), durante muito tempo, os conceitos de trabalho não faziam referência ao trabalho educacional, atividades de trabalho intelectual, como as de ensino, não eram consideradas formas de trabalho e só recentemente é que começaram a ser utilizados com essa finalidade. A autora assevera que as diversas transformações socioeconômicas e tecnológicas ocorridas ao longo do século contribuíram para que o trabalho docente passasse a ser visto como uma forma de trabalho. Assim, para Bronckart (2006, p. 203), somente "há alguns anos a atividade de ensino tende a ser considerada como um verdadeiro trabalho" (grifos do autor). A partir de então, o trabalho docente passou a ser discutido por vários pesquisadores do Interacionismo Sociodiscursivo (MACHADO, 2009; 2007; BRONCKART, 2006; 2008; MACHADO; CRISTOVÃO, 2009; GARCIA-REIS, 2020).

Partimos do pressuposto de que o trabalho docente apresenta uma grande complexidade e, por isso, uma formação na qual a prática seja contemplada se faz necessário. Entendemos que a formação docente precisa considerar não apenas os saberes acadêmicos, fundamentais, mas também aproximar o futuro docente do seu lócus de trabalho.

Nesse sentido, este artigo se ancora nos pressupostos teórico-metodológicos do Interacionismo Sociodiscursivo (ISD), assumindo a linguagem como atividade central do desenvolvimento humano, uma vez que é por meio dela que interagimos socialmente através dos discursos que produzimos.

Como objetivo, buscamos investigar se quatro dimensões de trabalho - atividade situada, prefigurada pelo próprio trabalhador, mediada por instrumentos materiais ou simbólicos e interacional -, das oito propostas por Machado 
(2007), estão presentes no trabalho docente da supervisora do Programa Institucional de Bolsa de Iniciação à Docência (Pibid) - Letras/Licenciatura - da Universidade Federal de Juiz de Fora (UFJF), uma vez que consideramos essas dimensões essenciais para o trabalho docente.

Os dados tomados para análise emergem de entrevistas semiestruturadas realizadas com egressos do Pibid e, para analisá-los, foram utilizadas duas categorias de segmentos decorrentes da distribuição dos turnos de fala, Segmentos de Orientação Temática (SOT) e Segmentos de Tratamento Temático (STT), conforme proposto por Bronckart (2008) e Bulea (2010).

As seções deste artigo contemplam, além desta introdução, o referencial teórico-metodológico que guiou o estudo; as práticas de linguagem; uma discussão sobre os conceitos de trabalho e trabalho docente; as considerações sobre o programa de formação Pibid e sua importância para a profissionalização do professor; as questões metodológicas assumidas; a análise dos dados e, finalmente, as considerações finais.

\section{Interacionismo Sociodiscursivo: bases filosóficas}

Nesta seção, pretendemos apresentar o quadro teórico-metodológico que utilizamos como suporte para o desenvolvimento da pesquisa, o Interacionismo Sociodiscursivo (ISD). Buscamos trazer os princípios interacionistas que regem o ISD, o trabalho de análise ao qual está direcionado e o diálogo com outras vertentes teóricas.

Em sua origem, o ISD é uma corrente teórico-metodológica idealizada pelo professor e pesquisador Jean-Paul Bronckart (1999), voltada para os estudos das relações entre a linguagem e o desenvolvimento humano. Seus referenciais têm raízes na filosofia de Spinoza, Marx e Vigotski, além de considerar também as obras de Voloshinov e Bakhtin (BRONCKART, 2006). Busca escopo teórico também em áreas como a Filosofia, Linguística, Sociologia e Psicologia (BRONCKART, 2006) para entender diversos fenômenos relacionados ao ensino e ao ensino como trabalho (BRONCKART, 2005). Dessa forma, as bases do ISD, de acordo com Bronckart (2006), podem ser distinguidas conforme as influências de ordem técnico-linguísticas e as de ordem epistemológicas/filosóficas. Assim, compreendemos que o autor configura o conjunto de seus trabalhos em uma abordagem transdisciplinar, que o auxilia a esclarecer as relações entre a linguagem, o agir e o desenvolvimento, assumindo um posicionamento epistemológico e político 
em relação aos seus estudos.

Tal como mencionado, os estudos de Bronckart se voltam para as relações entre a linguagem e o desenvolvimento humano. O pesquisador defende o papel central que a linguagem desempenha, não apenas no agir humano, mas também em seu funcionamento psíquico e em seu desenvolvimento. No Brasil, diversos autores, como Machado (2007, 2009), Abreu-Tardelli (2006), Guimarães (2007), Garcia-Reis (2020), entre tantos outros, têm voltado seus estudos para o ISD e desenvolvido pesquisas que o utilizam tanto como referencial para analisar o funcionamento e desenvolvimento das condutas humanas quanto como método de análise textual, contribuindo assim para a ampliação do seu quadro teórico-metodológico.

O Interacionismo Sociodiscursivo em que nos embasamos, em conformidade com Bronckart (1999), estabelece que as atividades coletivas são mediadas pela prática de linguagem e é "no quadro das avaliações sócio-discursivas [langagières] da atividade que as ações são delimitadas e os textos podem ser imputáveis a seres humanos particulares" (BRONCKART, 1999, p.107). De acordo com o autor, o pensamento consciente é produto da ação e da linguagem, determinado pelo discurso, e a relação das pessoas com o meio social em que estão inseridas se organiza a partir dessas premissas.

Em virtude do exposto, acreditamos na relevância do ISD para o desenvolvimento de pesquisas no campo educacional, já que, por sua natureza não só teórica, mas também prática e metodológica, permite a análise de textos referentes às diversas e multifacetadas atividades no e sobre o trabalho docente, como veremos adiante, e, com isso, uma maior compreensão do humano. Atualmente, de acordo com Abreu-Tardelli (2006), as pesquisas de Bronckart continuam direcionadas a buscar esse agir a partir da perspectiva da análise do trabalho e da linguagem no ou sobre o trabalho. Paralelamente a isso, observa-se a emergência de pesquisas com vistas ao desenvolvimento humano pelo e no trabalho. Para enriquecer esses estudos, O ISD tem buscado também aportes teóricos em outras disciplinas, como na Clínica da Atividade (CLOT, 2007) e na Ergonomia da Atividade (AMIGUES, 2004).

\subsection{Práticas de linguagem}

A espécie humana se organiza de maneira complexa e diversificada para a realização de suas formas de atividade. Esse processo só se tornou possível devido à emergência de uma forma de comunicação - a linguagem - que conferiu 
às atividades e organizações humanas uma dimensão particular - a social. A cooperação entre esses sujeitos na atividade é, portanto, "regulada e mediada por verdadeiras interações verbais" (BRONCKART, 1999, p. 32), caracterizando o agir comunicativo.

Endossando as afirmações do autor, Cadilhe; Garcia-Reis (2017) sugerem que a linguagem é uma prática social de interação verbal entre indivíduos de uma mesma comunidade da espécie humana. Os autores asseguram que toda produção linguística é realizada dentro de uma esfera social que fornece possibilidades e limitações para essa produção.

Nesse sentido, Bronckart (1999) define a linguagem humana como

uma produção interativa associada às atividades sociais, sendo ela o instrumento pelo qual os interactantes, intencionalmente, emitem pretensões à validade relativas às propriedades do meio em que essa atividade se desenvolve. A linguagem é, portanto, primariamente, uma característica da atividade social humana, cuja função maior é de ordem comunicativa ou pragmática (BRONCKART, 1999, p. 34).

Apoiando-nos nesses pressupostos, concebemos a linguagem como central no processo de desenvolvimento humano e entendemos que, por meio dela, interagimos socialmente, nos apropriando e recriando culturas que passam de geração em geração. Destacamos também, em conjunto com Cadilhe; Garcia-Reis (2017), que a concepção de linguagem viabilizada pelo interacionismo sociodiscursivo não se limita à expressão de processos psicológicos - percepção, emoções, cognição, sentimentos - direcionando-se também a ser um instrumento que concebe e organiza esses processos (BRONCKART, 2006) em perspectivas especificamente humanas.

Para Bronckart (2005), "o desenvolvimento histórico da atividade coletiva humana é indissociável da emergência da linguagem verbal" (BRONCKART, 2005, p. 237). A linguagem verbal é condição sine qua non para o desenvolvimento da atividade coletiva humana. Ela tem como função principal significar e construir sentido, além de regular a atividade em geral e representar os conhecimentos (BRONCKART, 2005).

Nesse contexto, as práticas de linguagem desenvolvidas a partir de uma situação comunicativa são concebidas pelo ISD como formas de ação dos sujeitos no mundo (CRISTOVÃO; VIEIRA, 2016). As autoras advogam que as línguas são práticas verbais inseridas num movimento ativo e dinâmico pertencente às interações verbais. Partindo desse princípio, Bronckart (2008, p. 109) defende que "a evolução humana deve ser apreendida em uma perspectiva dialética e histórica [...], em uma perspectiva que implica um necessário viés dialético". Apoiando-nos 
nos estudos de Bakhtin (2003), compreendemos que "todos os diversos campos da atividade humana estão ligados ao uso da linguagem" (BAKHTIN, 2003, p. 261), por meio de enunciados, os quais o autor denominou de gêneros do discurso.

O propósito do ISD é discutir o papel que a linguagem e as práticas de linguagem desempenham na constituição e no desenvolvimento das capacidades epistêmicas (ordem dos saberes) e praxeológicas (ordem do agir) dos seres humanos (BRONCKART, 2006). Nesse sentido, o autor sustenta que o objetivo do ISD é "demonstrar a interação entre os diferentes tipos de fenômenos mentais e comportamentais, pois é essa interação que é essencial ao ser humano, e não um ou outro dos fenômenos particulares que estejam nela envolvidos" (BRONCKART, 2006, p. 108, grifos do autor).

Na próxima seção, apresentamos alguns conceitos sobre o trabalho, trabalho docente e seus elementos constitutivos. Ressaltamos que esses conceitos poderão nos proporcionar um melhor entendimento sobre as concepções de trabalho dos alunos licenciandos entrevistados em nossa pesquisa.

\subsection{Trabalho e trabalho docente}

De acordo com Abreu-Tardelli (2006), na sociedade em que vivemos, o trabalho é considerado uma atividade central da existência humana e é por meio dele que o agir se manifesta de forma mais significativa. Para Bronckart (2008, p. 93), "o trabalho é uma forma de agir, ou uma prática, que seria própria da espécie humana" e se desenvolve a partir de atividades coletivas organizadas com o objetivo de assegurar a subsistência dos membros da sociedade. Há um intenso debate nas Ciências Humanas e nas Ciências do Trabalho sobre uma compreensão de trabalho que abarque todas as formas de agir humano desenvolvidas em diferentes espaços e momentos históricos. Para Bronckart (2006), o trabalho consiste em

um tipo de atividade ou de prática. [...] é um tipo de atividade própria da espécie humana, que decorre do surgimento, desde o início da história da humanidade, de formas de organização coletiva destinadas a assegurar a sobrevivência econômica dos membros de um grupo: tarefas diversas são distribuídas entre esses membros (o que se chama divisão de trabalho); assim, esses membros se veem com papéis e responsabilidades específicas a eles atribuídos, e a efetivação do controle dessa organização se traduz, necessariamente, pelo estabelecimento de uma hierarquia (BRONCKART, 2006, p. 209).

A noção da parte linguageira do trabalho (BRONCKART, 2008) refere-se 
a situações nas quais determinadas atividades (mecânicas ou corporais) podem ser substituídas, acompanhadas ou mesmo determinadas pelas produções linguageiras. Assim, os trabalhadores deveriam se expressar, falar, se comunicar e cooperar, ser sujeito da comunicação, entretanto, essa comunicação costuma ser sempre predefinida pela empresa (MACHADO, 2007).

Machado et al. (2009), inspiradas pelo Interacionismo Social, sustentam que as ações humanas não podem ser tomadas no fluxo contínuo do agir somente por meio da observação de condutas explícitas dos indivíduos, elas devem ser analisadas a partir de interpretações, produzidas pela utilização de um agir linguageiro, em textos próprios dos actantes ou observadores dessas ações. Dessa maneira, para compreendermos melhor a atividade educacional, o objeto de análise deixa de ser as condutas diretamente observáveis e direciona-se para os textos que são desenvolvidos na situação de trabalho e sobre essa atividade profissional. Nesse contexto, Bronckart (2008) ressalta que diversos debates e estudos dirigiram-se para as questões linguísticas e semióticas dos discursos no trabalho em variados segmentos profissionais.

Os aportes trazidos pela Ergonomia e pela Clínica da Atividade contribuíram sobremaneira para que Machado (2007) elaborasse uma definição, mesmo que provisória, do que compreende como trabalho do professor. Assim, com base em autores do ISD, da Ergonomia e da Clínica da Atividade (BRONCKART, 2008, 2006; AMIGUES, 2004; SAUJAT, 2004; CLOT, 2007), e fundamentando-se em uma leitura marxista da atividade do trabalho, a autora afirma que essa atividade pode ser compreendida a partir das seguintes dimensões:

a) É uma atividade situada, influenciada por um contexto mais imediato e mais amplo; É pessoal e sempre única, engajando o trabalhador em todas as suas dimensões (física, cognitiva, emocional, etc.); É impessoal, pois não se desenvolve de forma totalmente livre, pois as tarefas são prescritas, em um primeiro momento por instâncias externas e hierarquicamente superiores ao trabalhador;

b) É prefigurada pelo próprio trabalhador, na medida que ele reelabora as prescrições, construindo prescrições para si mesmo e guiando-se por objetivos que constrói para si mesmo, como uma solução de compromisso com o que as prescrições externas Ihe demandam, com a situação específica em que se encontra e com os próprios limites de seu funcionamento físico e psíquico;

c) É mediada por instrumentos materiais ou simbólicos, na medida em que o trabalhador se aproprie de artefatos socialmente construídos e disponibilizados para ele pelo meio social;

d) É interacional, pois sua interação é multidimensional e de mão dupla, pois ao agir sobre o meio com a utilização de instrumentos (materiais ou simbólicos), o trabalhador transforma esse meio e esses instrumentos e ao mesmo tempo é transformado por eles; 
e) É interpessoal, envolve a interação de vários sujeitos presentes na situação de trabalho e até mesmo os ausentes;

f) É transpessoal, pois é também guiada por modelos específicos do agir de cada ofício sócio historicamente construídos pelos coletivos de trabalho;

g) É conflituosa devido as escolhas que devem ser feitas frequentemente pelos trabalhadores para (re)direcionar seu agir em diferentes situações contraditórias do agir de outros envolvidos, do meio, dos artefatos, das prescrições, entre outros;

h) Fonte de aprendizagem de novos conhecimentos e para o desenvolvimento de capacidades do trabalhador devido a seu caráter conflituoso; ou fonte de impedimento para novas aprendizagens e para esse desenvolvimento, quando o trabalhador se vê frente a dilemas intransponíveis que Ihe amputam o seu agir [...] (MACHADO, 2007, p. 91-92, destaques da autora).

Considerando tais dimensões, a autora conceitua o trabalho docente como

[...] uma mobilização, pelo professor, de seu ser integral, em diferentes situações de planejamento, de aula, de avaliação -, com o objetivo de criar um meio que possibilite aos alunos a aprendizagem de um conjunto de conteúdos de sua disciplina e o desenvolvimento de capacidades específicas relacionadas a esses conteúdos, orientando-se por um projeto de ensino que é prescrito por diferentes instâncias superiores e com a utilização de instrumentos obtidos do meio social e na interação com diferentes outros que, de forma direta ou indireta, estão envolvidos na situação (MACHADO, 2007, p. 93).

Nesse viés, Machado (2009) sustenta que o trabalho é uma atividade complexa, conflituosa, pois exige que o trabalhador faça uma série de escolhas para enfrentar diversos conflitos com o outro e com o meio, mobilizando artefatos e prescrições.

\section{Pibid como instância formativa para a profissionalização docente}

Nesta seção, iremos discutir alguns aspectos do Programa Institucional de Bolsa de Iniciação à Docência (Pibid), que tem como propósito a oferta de uma formação de qualidade voltada para a profissionalização dos futuros docentes das diversas licenciaturas.

No interior das inúmeras discussões decorrentes da formação inicial de professores, pesquisas apontam que as novas exigências referentes ao trabalho dos professores na atual sociedade e a constatação de que a formação inicial para o trabalho docente não vem oferecendo os conhecimentos e habilidades necessários para enfrentar os desafios da docência colocaram em evidência a atuação da universidade na formação dos docentes (GATTI et al., 2014). As autoras ressaltam alguns problemas referentes à estrutura e à dinâmica dos currículos 
dos cursos de formação docente e apontam como um dos principais desafios as relações entre teoria e prática, formação acadêmica e o trabalho na escola. Esses aspectos, identificados na pesquisa das autoras, têm fomentado a emergência de programas em diversas esferas, federais, estaduais ou municipais, objetivando "estreitar as relações entre teoria e prática e favorecer a inserção na docência" (GATTI et al., 2014, p. 9).

Nesse contexto, diversas iniciativas de órgãos gestores das políticas educacionais, com vistas a qualificar a formação docente, buscaram implantar programas que aproximassem a escola da universidade e favorecessem a inserção do futuro professor no seu campo profissional (ANDRÉ, 2016). Entre esses programas, destacamos o Pibid, proposto pelo MEC/CAPES. O Pibid vem se destacando nos últimos anos como uma das mais significativas políticas de formação docente. Em âmbito nacional, um "entre lugar" destinado à formação docente.

Atualmente, o programa é mantido apenas pela CAPES e tem como orientações gerais a promoção da inserção dos estudantes no contexto das escolas públicas desde o início da sua formação acadêmica para que desenvolvam atividades didático-pedagógicas sob orientação de um docente da licenciatura e de um professor da escola. Gatti et al (2014) consideram também que o objetivo desse programa é desenvolver mudanças na postura formativa de docentes para a educação básica no âmbito das Instituições de Ensino Superior (IES).

A criação do Pibid "teve a intenção de fomentar a iniciação à docência com a finalidade de melhor qualificá-la, mediante projeto específico de trabalho e concessão de bolsas, abrangendo as diferentes áreas do conhecimento que fazem parte do currículo da educação básica" (GATTl et al, 2014, p. 9). Um dos diferenciais nesse programa é a concessão de bolsas, não apenas aos graduandos, mas também aos professores das universidades que os orientam e aos professores das escolas públicas (supervisores) que acompanham as atividades dos bolsistas no âmbito escolar. Esses professores supervisores atuam como co-formadores nesse processo de iniciação à docência, e estão em diálogo constante com o professor formador da universidade, formando uma rede de colaboração.

O Pibid prevê a participação ativa do licenciando não apenas nas atividades didáticas, mas também incita sua participação na criação de experiências metodológicas, tecnológicas; no desenvolvimento de práticas inovadoras e interdisciplinares dentro e fora da sala de aula, utilizando variados materiais e recursos (ANDRÉ, 2016). Assim, entendemos, em conjunto com a autora, que o programa oportuniza uma formação mais abrangente tanto no que se refere aos conteúdos quanto às estratégias didáticas. 
Nessa direção, argumentamos que o Pibid valoriza a escola como um campo de formação para a docência, articulando teoria e prática. Além disso, destacamos que o trabalho compartilhado entre os licenciandos, os professores das escolas e o professor formador leva a escola para dentro da universidade e a universidade para dentro da escola. Portanto, entendemos que o Pibid se configura como um terceiro espaço, um lugar híbrido, de ligação e vínculo entre as distintas realidades que compõem a profissão docente (NÓvOA, 2017). De acordo com o autor, a construção desse "entre-lugar" não se configura em mais uma reorganização interna das universidades e licenciaturas, mas sim num lugar de ligação e articulação entre a universidade, as escolas e as políticas públicas.

Admitimos, assim como Bronckart (2006), que a análise das práticas formativas deve ser o eixo central dos estudiosos das Ciências da Educação, que devem buscar investigar teórica e metodologicamente o estatuto do agir docente, de suas condições de realização e de suas condições de avaliação e interpretação. De acordo com Bronckart (2006), a análise das práticas do agir, ou do trabalho, tornou-se mecanismo central nos dispositivos de formação docente.

A transmissão de saberes ou de procedimentos formais permanece indispensável à formação docente, e as capacidades praxiológicas construídas dentro dos mecanismos de análise das práticas deveriam estar vinculadas aos saberes coletivos (BRONCKART, 2006). O autor enfatiza que o objetivo da formação não é uma melhor eficácia nas situações de trabalho real dos formandos, mas sim fornecer recursos para o seu desenvolvimento como profissional.

\section{Metodologia}

Esta pesquisa se desenvolveu utilizando como principal aporte teórico-metodológico o Interacionismo Sociodiscursivo - ISD - (BRONCKART, 1999, 2006, 2008). Como já explicitado anteriormente, o ISD busca investigar o agir humano através da linguagem, entendida como uma atividade social específica ou uma atividade de discurso. De acordo com Bronckart (2008), a atividade de linguagem é significante e produtora de conteúdos e expressões, portanto, não deve ser considerada uma simples produção de signos materiais para significados prontos.

Os dados tomados para análise emergem de entrevistas semiestruturadas (MOREIRA; CALEFFE, 2008) com os alunos egressos do Pibid, graduandos do curso de Letras/Licenciatura. Compreendemos que as entrevistas semiestruturadas permitem "obter visões individuais dos entrevistados sobre um tema" (FLICK, 2013, p. 115), suscitando um diálogo entre entrevistador e entrevistado. De acordo 
com Flick (2013), esse instrumento permite aos entrevistados responderem de forma mais livre e extensiva, além disso, permite também que o entrevistador aprofunde o tema, caso as respostas não sejam suficientes.

As entrevistas foram realizadas de forma remota, por videoconferência, devido à pandemia de COVID-19 que assolou o país a partir do ano de 2020. Foram entrevistados sete egressos do Pibid, ainda licenciandos do curso de Letras no momento da pesquisa, aqui denominados de Nádia, Maria, Rita, Léia, Chay, Vanea e Ana. Segundo Bronckart (2008), as entrevistas permitem que os entrevistados expliquem ou comentem o seu agir, a sua participação no agir, apresentando o contexto e as condições de realização do agir.

A pesquisa aqui apresentada é um recorte de um estudo de mestrado defendido em 2021 que buscou investigar as dimensões de trabalho a partir das interações com os licenciandos. Neste artigo, nos propomos a investigar se quatro dimensões de trabalho - atividade situada, prefigurada pelo próprio trabalhador, mediada por instrumentos materiais ou simbólicos e interacional -, das oito propostas por Machado (2007), estão presentes no trabalho docente da supervisora do Pibid - Letras/Licenciatura - da Universidade Federal de Juiz de Fora (UFJF). A escolha pelas quatro dimensões aqui abordadas se deu a partir da relevância dada a elas pelos estudantes.

Bronckart aponta que para analisar uma entrevista é necessário "[...] a elaboração de classificações das dimensões do agir-referente consideradas [...] com base nos conteúdos temáticos efetivamente presentes nos textos" (BRONCKART, 2008, p. 162). Dessa maneira, o autor sustenta que as entrevistas devem ser separadas, primeiramente, em duas categorias de segmento: i) segmentos de introdução, de apresentação ou de lançamento de um tema, denominados de Segmentos de Orientação Temática (SOT), produzidos pelo entrevistador; ii) segmentos produzidos pelo entrevistado em resposta a uma questão ou dando prosseguimento a um lance temático do entrevistador, em que o tema é efetivamente tratado, os quais são chamados de Segmentos de Tratamento Temático (STT).

Na próxima seção, apresentaremos a análise e interpretação dos dados gerados a partir dos SOTs, Sub-SOTs e STTS, conforme os quadros produzidos.

\section{0 trabalho docente sob a ótica dos alunos egressos do Pibid: analisando o trabalho docente da professora supervisora}

Nesta seção, apresentaremos discussões sobre os dados obtidos. Anali- 
samos, a partir da perspectiva do aluno pibidiano, quatro dimensões que estão presentes no trabalho docente da professora supervisora.

\subsection{Situada, pessoal e impessoal}

A primeira dimensão apresentada pela autora é: atividade situada, pessoal, sempre única e impessoal. Observamos que a pesquisadora subdividiu essa primeira dimensão - atividade situada - em três: (1) situada, (2) pessoal e sempre única e (3) impessoal. Desse modo, denominamos cada uma como um SUB-SOT diferente para a análise dos dados.

O primeiro SUB-SOT, portanto, é "atividade situada", ou seja, aquela que sofre influência do contexto mais imediato, mas também de um contexto mais amplo. Preparar-se para o agir docente requer o conhecimento dos saberes a ensinar, além disso, exige também combinar as diferentes situações de ensino para planificar as intervenções necessárias (DOLZ, 2017). Para esse SUB-SOT, encontramos o seguinte STT que gostaríamos de destacar:

\section{Quadro 1 - SOT: trabalho do professor supervisor do Pibid, SUB-SOT: atividade} situada, STT 1: Muito situada

\begin{tabular}{|c|c|c|c|c|}
\hline & SOT & SUB-SOT & STT & Trechos da entrevista \\
\hline $\begin{array}{l}\text { O1 } \\
\text { O2 } \\
03 \\
04 \\
05 \\
06 \\
07 \\
08 \\
09 \\
10 \\
11 \\
12 \\
13 \\
14 \\
15 \\
16 \\
17 \\
18 \\
19 \\
20\end{array}$ & $\begin{array}{l}\text { TRABALHO } \\
\text { DO } \\
\text { PROFESSOR } \\
\text { SUPERVISOR } \\
\text { DO PIBID }\end{array}$ & $\begin{array}{l}\text { Atividade } \\
\text { situada }\end{array}$ & Muito situada & $\begin{array}{l}\text { "as vezes sofria influência do } \\
\text { contexto também. Que os alunos } \\
\text { viam em casa e traziam pra sala de } \\
\text { aula" - Nádia } \\
\text { "a atividade que a Carol gerava era } \\
\text { sempre muito situada" - Léia } \\
\text { "Eu acho muito que o trabalho da } \\
\text { Carol é muito situado." - Rita } \\
\text { "Sim, eu posso dizer que ela foi } \\
\text { situada sim, que ela procurava as } \\
\text { questões do meio, assim, as questões } \\
\text { do contexto ali que estavam } \\
\text { acontecendo, principalmente do } \\
\text { país e a questão social." - Maria }\end{array}$ \\
\hline
\end{tabular}

Fonte: Elaborado pelas autoras. 
Podemos perceber a partir dos excertos que a atividade da professora supervisora é situada tanto pelo contexto cultural quanto político e social mais amplo. Essa percepção evidencia que as mudanças que acontecem tanto no país quanto na região afetam diretamente a atividade docente. Reafirmando essa ideia, Dolz (2017) destaca que o contexto sócio-histórico, o sistema educacional e o sistema de ensino exercem influência sobre o agir do professor. $\bigcirc$ autor enfatiza que os contextos sociais do Brasil estão intrinsecamente e continuamente relacionados à atividade docente. Nesse viés, fica evidente que a atividade do professor não se limita ao ensino, ela se relaciona também a um conjunto amplo de funções educativas sobre uma grande variedade de aspectos (DOLZ, 2017).

O próximo quadro irá tratar do SUB-SOT "pessoal e sempre única". Buscamos, dessa forma, compreender se o trabalho da professora supervisora envolve a totalidade das dimensões do trabalhador - físicas, mentais, práticas, emocionais etc. Assumimos, juntamente com Clot (2010, p. 4), que "O homem no trabalho não se limita a ser um simples sistema de tratamento da informação, tampouco uma simples ferramenta de trabalho dotada de uma força mecânica mais ou menos sob controle", portanto, acreditamos que há dimensões subjetivas que funcionam como forças motrizes atreladas à atividade de trabalho. A seguir está o STT desse SUB-SOT:

Quadro 2 - SOT: trabalho do professor supervisor do Pibid, SUB-SOT: é pessoal e sempre único, STT: Sempre diferente

\begin{tabular}{|l|l|c|l|l|}
\hline & SOT & SUB-SOT & STT & Trechos da entrevista \\
\hline 01 & & & & "Sim, eu acho que era sempre \\
02 & TRABALHO & & & diferente porque não tem uma \\
03 & DO & É pessoal & & fórmula certa pra seguir, né?" - \\
04 & PROFESSOR & e sempre & Sempre diferente & Vanea \\
05 & SUPERVISOR & único & & \\
06 & DO PIBID & & & "Sim. Eu acho que é pessoal e \\
07 & & & sempre única mesmo." - Rita \\
\hline
\end{tabular}

Fonte: Elaborado pelas autoras.

Identificamos, a partir das respostas dos entrevistados, que há uma pessoalidade na atividade da professora supervisora. Compreendemos que essa dimensão "pessoal e sempre única" está presente nas atividades da docente, pois não há como reduzir o trabalhador à atividade de trabalho (CLOT, 2010), ele possui uma subjetividade e essa está diretamente implicada no seu agir. 
Destacamos também a heterogeneidade de cada sala de aula. Essa característica é muito marcante, pois ela faz com que a atividade docente seja sempre única. Há diferenças significativas em cada turma, os alunos possuem diferentes capacidades e possibilidades sociais (TARDIF; LESSARD, 2014), sua capacidade de aprender, suas possibilidades de engajar-se a uma tarefa, tudo varia. Assim, apoiando-nos nos estudos de Tardif; Lessard (2014), admitimos que não existe uma relação típica, uniforme e universal entre professor e aluno, o que pode ser reiterado pela fala da entrevistada Vanea: "não tem uma fórmula certa para seguir, né".

As prescrições direcionadas ao trabalho do professor marcam a impessoalidade no agir desse profissional, uma vez que, elaboradas por instâncias hierarquicamente superiores, precisam ser cumpridas. A respeito da atividade docente da professora supervisora ser "impessoal", vejamos as respostas dos entrevistados no quadro abaixo:

\section{Quadro 3 - SOT: trabalho do professor supervisor do Pibid, SUB-SOT: impessoal, STT: Parcialmente impessoal}

\begin{tabular}{|c|c|c|c|c|}
\hline & SOT & SUB-SOT & STT & Trechos da entrevista \\
\hline $\begin{array}{l}01 \\
02 \\
03 \\
04 \\
05 \\
06 \\
07 \\
08 \\
09 \\
10 \\
11 \\
12 \\
13 \\
14 \\
15\end{array}$ & $\begin{array}{l}\text { TRABALHO } \\
\text { DO } \\
\text { PROFESSOR } \\
\text { SUPERVISOR } \\
\text { DO PIBID }\end{array}$ & Impessoal & $\begin{array}{c}\text { Parcialmente } \\
\text { impessoal }\end{array}$ & $\begin{array}{l}\text { "...realmente ela tomava como } \\
\text { base o Pism." - Nádia } \\
\text { "Então eu não creio que seja, que } \\
\text { possa ser totalmente impessoal } \\
\text { sabe" - Vanea } \\
\text { "Sim. Porque ela tinha um } \\
\text { programa pra cumprir também." - } \\
\text { Maria } \\
\text { "Eu acho que ela tinha bastante } \\
\text { liberdade para elaboraro conteúdo } \\
\text { dela" - Ana }\end{array}$ \\
\hline
\end{tabular}

Fonte: Elaborado pelas autoras.

Conforme Bronckart (2006), o trabalho prescrito é predefinido por diversos documentos que dão instruções aos trabalhadores. Constituem-se como 
uma representação do que deve ser o trabalho, antecipando e fornecendo uma imagem do agir. No trabalho educacional, temos diversos textos que prefiguram o agir do professor em contexto escolar. Esses textos buscam homogeneizar o trabalho escolar, podendo incidir sobre toda a organização da escola, bem como sobre o trabalho a ser realizado (BRONCKART; MACHADO, 2004).

Observamos que as respostas variam muito em relação à dimensão da impessoalidade. Há uma consonância de que existe um programa a ser cumprido, entretanto, os alunos entrevistados deixam claro que a professora tem liberdade para executar essas prescrições. Por isso, entendemos que a atividade da docente em análise é parcialmente impessoal.

Nesse contexto, aduzimos que o professor não é apenas alguém que aplica conhecimentos produzidos por outros, ou seja, um agente determinado por mecanismos prescritivos, ele é um ator, "um sujeito que assume sua prática a partir dos significados que ele mesmo the dá, um sujeito que possui conhecimentos e um saber-fazer provenientes de sua própria atividade e a partir dos quais ele a estrutura e a orienta" (TARDIF, 2000, p. 115).

Destacamos ainda a importância da formação docente para a formação de professores críticos e reflexivos (ANDRÉ, 2016), capazes de realizar mudanças e ajustes necessários para que a ação docente seja efetiva. Portanto, segundo André (2016), pretende-se formar sujeitos autônomos com ideias próprias, que decidam qual o melhor caminho a ser seguido, implementando ações necessárias para alcançar o seu objetivo.

A próxima dimensão de trabalho posta por Machado (2007) está intimamente atrelada à dimensão impessoal. Vejamos a seguir.

\subsection{Prefigurada pelo próprio trabalhador}

É consenso que em qualquer atividade de trabalho o trabalhador irá encontrar diversas restrições, explicitadas em textos instrucionais ou procedimentais, provenientes das instituições, que configuram inicialmente suas ações (MACHADO, 2009). Conforme a pesquisadora, frequentemente esses textos definem as tarefas de cada trabalhador, seus objetivos, até mesmo os resultados esperados de suas ações, definindo as responsabilidades dos agentes envolvidos.

No âmbito do trabalho docente não é diferente, as prescrições desempenham um importante papel nas atividades, pois são desencadeadoras da ação do professor (AMIGUES, 2004). Todavia, Amigues (2004) ressalta que o trabalho do professor pode se engajar em prescrições vagas e isso permite que ele redefi- 
na para si as tarefas que Ihe são prescritas, reorganizando sua atividade. É nesse sentido que Machado (2007) afirma que a atividade do trabalho: "é prefigurada pelo próprio trabalhador" (MACHADO, 2007, p. 91, grifos nossos).

Portanto, concordamos com Guimarães (2007) quando ela pondera que as prescrições são "importantes na medida em que cabe ao docente mediar uma prescrição inicial até que seja realizada junto aos alunos". Sobre essa dimensão do trabalho, vejamos o quadro abaixo com o STT produzido por esse SUB-SOT:

\section{Quadro 4 - SOT: trabalho do professor supervisor do Pibid, SUB-SOT: prefigurada pelo próprio trabalhador, STT: Prefigurada com liberdade de ação}

\begin{tabular}{|c|c|c|c|c|}
\hline & SOT & SUB-SOT & STT & Trechos da entrevista \\
\hline $\begin{array}{l}01 \\
02 \\
03 \\
04 \\
05 \\
06 \\
07 \\
08 \\
09 \\
10 \\
11 \\
12 \\
13 \\
14 \\
15 \\
16 \\
17 \\
18 \\
19 \\
20 \\
21 \\
22\end{array}$ & $\begin{array}{l}\text { TRABALHO DO } \\
\text { PROFESSOR } \\
\text { SUPERVISOR } \\
\text { DO PIBID }\end{array}$ & $\begin{array}{l}\text { Prefigurada } \\
\text { pelo próprio } \\
\text { trabalhador }\end{array}$ & $\begin{array}{c}\text { Prefigurada } \\
\text { com liberdade } \\
\text { de ação }\end{array}$ & $\begin{array}{l}\text { "com certeza, porque ela } \\
\text { sempre fazia roteiro das } \\
\text { coisas que ela gostaria de } \\
\text { trabalhar com as turmas." - } \\
\text { Léia } \\
\text { "Essa questão de reelaborar } \\
\text { as prescrições do próprio } \\
\text { trabalho isso é muito do } \\
\text { professor né." - Vanea } \\
\text { "ela reconstruiu aquilo } \\
\text { conforme a didática dela" - } \\
\text { Rita } \\
\text { "Ela cumpriu com tudo que } \\
\text { estava ali previsto, mastendo } \\
\text { liberdade de escolher textos, } \\
\text { de escolher a maneira que } \\
\text { ela queria trabalhar." - Ana }\end{array}$ \\
\hline
\end{tabular}

Fonte: Elaborado pelas autoras.

Compreendemos que as prescrições estão marcadamente presentes no trabalho docente, uma vez que o professor se encontra imerso em um sistema hierarquicamente organizado. Nesse sentido, os docentes sempre são colocados frente a prescrições diversas que precisam ser reelaboradas. Bronckart (2008) assinala que todos os textos servem para estruturar as condutas humanas, atribuindo a elas um valor interpretativo que auxiliam na construção de modelos de agir. 
Portanto, o agir humano pode ser reconfigurado nos e pelos textos.

Nesse viés, entendemos que a formação docente deve trazer um diálogo profícuo entre os futuros docentes sobre os diversificados textos que prescrevem o agir do professor, uma vez que são várias as tentativas de desprofissionalizar a docência (NÓVOA, 2017). Portanto, devemos compreender essas questões e discuti-las em diferentes espaços, preparando os professores para além dos aspectos técnicos, científicos ou pedagógicos.

Parece-nos que os alunos entrevistados, mesmo identificando que há prescrições a serem seguidas, reconheceram que há certa atorialidade no trabalho da professora supervisora, isso porque o trabalho do professor não pode ser visto de forma mecânica, "sendo a atividade educacional constitutivamente interativa, é preciso considerar que nele emerge uma dimensão de liberdade" (MACHADO, 2009, p.83).

\subsection{Mediada por instrumentos materiais ou simbólicos}

Para exercer o seu agir, os professores buscam utilizar artefatos materiais ou simbólicos disponibilizados pelo meio social. A ideia de mediação está no centro das reflexões vigotskianas e intimamente atrelada ao conceito de instrumento psicológico (FRIEDRICH, 2012). Para a autora, as funções psíquicas superiores surgem com o auxílio dos instrumentos psicológicos constituídos como fenômenos psíquicos mediatizados. Esses instrumentos facilitam a memorização demandada, pois novos vínculos são criados. Nesse sentido, Friedrich (2012) ressalta que os processos psíquicos são compostos por três elementos, a saber: a tarefa, o instrumento e o processo psíquico necessário para a resolução da tarefa.

Vigotski, ampliando o conceito de signo, destaca que todos os signos possíveis (a linguagem, os símbolos algébricos, as obras de artes, diagramas, mapas, planos etc.), considerando que qualquer objeto da realidade pode tornar-se um signo, são instrumentos psicológicos (FRIEDRICH, 2012). Nessa mesma direção, Machado (2009) reforça que a relação entre os sujeitos e o mundo não se dá de forma direta, mas mediada por artefatos culturais mediadores. Nesse SUB-SOT, identificamos o seguinte STT: 
Quadro 5 - SOT: trabalho do professor supervisor do Pibid, SUB-SOT: mediada por instrumentos materiais ou simbólicos, STT: Mediatizada por textos

\begin{tabular}{|c|c|c|c|c|}
\hline & SOT & SUB-SOT & STT & Trechos da entrevista \\
\hline $\begin{array}{l}01 \\
02 \\
03 \\
04 \\
05 \\
06 \\
07 \\
08 \\
09 \\
10\end{array}$ & $\begin{array}{l}\text { TRABALHO } \\
\text { DO } \\
\text { PROFESSOR } \\
\text { SUPERVISOR } \\
\text { DO PIBID }\end{array}$ & $\begin{array}{c}\text { Mediada por } \\
\text { instrumentos } \\
\text { materiais ou } \\
\text { simbólicos }\end{array}$ & $\begin{array}{c}\text { Mediatizada } \\
\text { por textos }\end{array}$ & $\begin{array}{l}\text { "sempre fez uso de quadro e } \\
\text { texto suporte..." - Nádia } \\
\text { "Sim. Toda aula ela tinha um } \\
\text { texto" - Maria } \\
\text { "mas ela se apropriava de vários } \\
\text { textos, toda aula tinha texto que } \\
\text { ela levava" - Chay }\end{array}$ \\
\hline
\end{tabular}

Fonte: Elaborado pelas autoras.

Observamos, a partir das entrevistas, que a professora supervisora utiliza o quadro e textos como principais instrumentos de mediação, sua atividade é, portanto, mediatizada. Friedrich (2012) compreende que na atividade mediatizada o sujeito intervém diretamente na natureza por meio de instrumentos. Ao introduzir o conceito de mediação, Vigotski não a tomou simplesmente como ponte, para ele a mediação provoca transformações, possui intencionalidade e promove desenvolvimento, enfim, é uma condição externa que potencializa o ato de trabalho, seja ele prático ou teórico.

Um dado recorrente nas respostas foi referente à utilização do texto como suporte para a atividade docente da professora supervisora. Eles, que são verdadeiros correspondentes empíricos das atividades de linguagem, são unidades comunicativas globais (BRONCKART, 2008) que precisam ser didatizados para servirem de instrumentos mediatizantes do trabalho docente. Nesse contexto, Bronckart (2006) reforça a necessidade da transposição desses materiais, ou seja, adaptá-los, considerando-se o que é viável realizar a partir de uma determinada situação didática. A partir de então, esses instrumentos serviam como mediatizadores da interação entre a professora supervisora e os alunos, o que nos reporta à próxima dimensão de trabalho.

\subsection{Interacional}

De acordo com Bronckart (2005), a linguagem é um instrumento capaz de propiciar a negociação e o acordo nas atividades humanas, ela "organiza, co- 
menta, regula as ações e interações humanas" (BRONCKART, 2005, p. 235). Nesse sentido, ainda de acordo com os estudos do autor, a linguagem se operacionaliza por meio dos discursos produzidos nas interações sociais, portanto, os discursos se inscrevem em um "horizonte social e se dirigem a um auditório social" (BRONCKART, 2008, p. 75).

Entendemos que o trabalho docente é permeado pela dimensão interacional, pois é preciso considerar que o centro da atividade educacional são as interações entre professor e alunos. Nossa hipótese é validada no SUB-SOT "interacional":

Quadro 7 - SOT: trabalho do professor supervisor do Pibid, SUB-SOT: interacional, STT: Aula baseada na interação

\begin{tabular}{|c|c|c|c|c|}
\hline & SOT & SUB-SOT & STT & Trechos da entrevista \\
\hline $\begin{array}{l}01 \\
02 \\
03 \\
04 \\
05 \\
06 \\
07 \\
08 \\
09 \\
10 \\
11 \\
12 \\
13 \\
14 \\
15 \\
16 \\
17 \\
18\end{array}$ & $\begin{array}{l}\text { TRABALHO } \\
\text { DO } \\
\text { PROFESSOR } \\
\text { SUPERVISOR } \\
\text { DO PIBID }\end{array}$ & Interacional & $\begin{array}{c}\text { Aula baseada } \\
\text { na interação }\end{array}$ & $\begin{array}{l}\text { "Ela sempre dava voz para os } \\
\text { alunos e fazia eles participar } \\
\text { também." - Nádia } \\
\text { "Com certeza a gente vê que a } \\
\text { postura é da Carol em sala de aula } \\
\text { é super sociointeracionista" - Léia } \\
\text { "...eu acho que é isso que permeia } \\
\text { a aula da Carol" - Rita } \\
\text { "O tempo todo... é totalmente } \\
\text { interacional" - Ana } \\
\text { "Sim, era bastante," - Chay }\end{array}$ \\
\hline
\end{tabular}

Fonte: Elaborado pelas autoras.

Tardif e Lessard (2014, p. 235) ressaltam que a interatividade caracteriza o principal objeto do trabalho do professor, pois "o essencial de sua atividade profissional consiste em entrar numa classe e deslanchar um programa de interações com os alunos". Os excertos retirados das entrevistas apontam que a aula da professora supervisora do Pibid é totalmente interativa, mediada pela linguagem. 
Observamos que os pibidianos enfatizam muito o trabalho da professora na sala de aula, permitindo-nos aduzir que para eles o trabalho docente se resume a dar aulas. No entanto, sustentamos que o trabalho docente é muito mais que isso. $O$ trabalho do professor é heterogêneo e comporta ações e atividades para além da sala de aula como, por exemplo, ações relacionadas a objetivos reais - modificar um comportamento, realizar uma tarefa; ações relacionadas a normas - respeitar a disciplina, privilegiar alguns valores; ações tradicionais - seguir os regulamentos da escola; e também ações afetivas - motivação, laços afetivos com os alunos, condição emocional da professora etc (TARDIF; LESSARD, 2014). Além disso, atividades como preencher diário, elaborar relatórios de alunos, pesquisar atividades para serem desenvolvidas em sala de aula, entre outras, fazem parte do cotidiano do docente.

A partir do estudo empreendido, identificamos a presença das quatro dimensões investigadas no trabalho da professora supervisora do Pibid, assim, inferimos que essas dimensões caracterizam não só o trabalho de modo geral, mas também se presentificam no trabalho docente.

\section{Considerações finais}

O objetivo deste artigo foi apresentar uma pesquisa, como já exposto anteriormente, que investigou se quatro dimensões de trabalho, a partir das oito propostas por Machado (2007), estavam presentes no trabalho docente da supervisora do Pibid. A partir das entrevistas com os egressos do programa que acompanharam as aulas e as atividades docentes desta professora, foi evidenciada a presença das quatro dimensões investigadas. Nessa direção, assumimos a concepção de que o trabalho docente não deve ser considerado um dom, mas sim um trabalho que exige formação e preparo, portanto, deve ser considerado um verdadeiro trabalho.

Consideramos que este estudo poderá contribuir para suscitar, no meio acadêmico-profissional, reflexões sobre o grande potencial formativo do Pibid para a profissionalização para o trabalho docente. Compreendemos que cabe aos professores e pesquisadores, em uma ação conjunta, aproximar a escola da universidade, priorizando uma práxis formativa a partir de uma formação na imersão. Sustentamos que esse é um caminho para alterar o quadro da formação de professores, pois assim é possível revelar como se dá o trabalho docente no contexto da profissão, para que novos modelos do agir possam ser construídos e 
para que, desvelando esse trabalho, consigamos também resgatar a valorização social do professor.

\section{Referências}

ABREU-TARDELLI, L. dos S. Aportes para compreender o trabalho do professor iniciante em EAD. 2006. 196 f. Tese (Doutorado em Linguística Aplicada e Estudos da Linguagem), Pontifícia Universidade Católica de São Paulo, São Paulo, 2006. Disponível em: https://tede2.pucsp.brl. Acesso em: 02 jan. 2021.

ANDRÉ, M. Formar o professor pesquisador para um novo desenvolvimento profissional. In: ANDRÉ, M. (Org.). Práticas inovadoras na formação de professores. Campinas: Papirus, 2016, p. 17-34.

AMIGUES, R. Trabalho do professor e trabalho de ensino. In: MACHADO, A. R. (Org.). 0 ensino como trabalho: uma abordagem discursiva. Londrina: Eduel, 2004, p. 35-54.

BAKHTIN, M. Estética da criação verbal. 4. ed. Trad. Paulo. Bezerra. São Paulo: Martins Fontes, 2003.

BRONCKART, J.P. Atividades de linguagem, textos e discursos: por um interacionismo sócio-discursivo. São Paulo: Educ, 1999.

BRONCKART, J. P.; MACHADO, A. R. (Org.). Procedimentos de análise de textos sobre o trabalho educacional. In: MACHADO, A. R. (Org.). O ensino como trabalho: uma abordagem discursiva. Campinas: Mercado de Letras, 2004, p. 131-163.

BRONCKART, J. P. Restrições e liberdades textuais, inserção social e cidadania. Revista da Anpoll, [s.l.], v. 1, n. 19, 2005. Disponível em: https://revistadaanpoll.emnuvens.com.br/revista/article/view/467. Acesso em: 02 jan. 2021.

BRONCKART, J. P. Atividade de linguagem, discurso e desenvolvimento humano. Tradução de Anna Raquel Machado e Maria de Lourdes Meirelles Matencio. Campinas: Mercado de Letras, 2006.

BRONCKART, J. P. O agir nos discursos: das concepções teóricas às concepções dos trabalhadores. Campinas: Mercado de Letras, 2008.

BUENO, Luzia. A construção de representações sobre o trabalho docente: o papel do estágio. 2007. 220 f. Tese (Doutorado em Linguística) - Pontifícia Universidade Católica de São Paulo, São Paulo, 2007. Disponível em: https://tede2.pucsp.br/handle/handle/13919. Acesso em: 02 jan. 2021.

BULEA, Ecaterina. Linguagens e efeitos desenvolvimentais da interpretação da atividade. Campinas: Mercado de Letras, 2010.

CADILHE, A. J.; GARCIA - REIS, A. R. Letramentos na formação de professores a partir de uma concepção discursiva da linguagem: reflexões propositivas. In: MAGALHÃES, T.; GARCIA-REIS, A. R.; FERREIRA, H. (Org.). Concepção discursiva de linguagem: ensino e formação docente. Campinas: Pontes Editores, 2017, p. 213-233. 
CLOT, Y. A função psicológica do trabalho. Tradução de Adail Sobral. 2 ed. Petrópolis, RJ: Vozes, 2007.

CLOT, Y. Trabalho e poder de agir. Belo Horizonte: Fabrefactum, 2010.

CRISTOVÃO, V. L. L; VIEIRA, I. R. Letramentos em língua portuguesa e inglesa na educação superior brasileira: marcos e perspectivas. Ilha do Desterro, Florianópolis, v. 69, n. 3, p. 209-221, set/ dez. 2016. Disponível em: http://www.scielo.br/j/ides/a/Rk9TrVKjydTXkFXgCPszmCL/abstract/?lan$\mathrm{g}=$ pt. Acesso em: 02 jan. 2021.

DOLZ, J. Prefácio. In: BARROS, E. M. D. de; CORDEIRO, G. S; GONÇALVES, A. V. (Org.). Gestos didáticos para ensinar a língua: agir docente e gêneros textuais. Campinas: Pontes Editores, 2017, p. 7-12.

FLICK, U. Introdução à metodologia científica: um guia para iniciantes. Porto Alegre: Penso, 2013.

FRIEDRICH, J. Lev Vigotski: mediação, aprendizagem e desenvolvimento: uma leitura filosófica e epistemológica. Campinas: Mercado de Letras, 2012.

GARCIA-REIS. A. R. A concepção do trabalho docente em documentos prescritivos. Reflexão e Ação. v. 28, p. 89-103, 2020. Disponível em: https://online.unisc.br/seer/index.php/reflex/article/ view/14299. Acesso em: 02 jan. 2021.

GATTI, B. A. et al. Um estudo avaliativo do Programa Institucional de Bolsa de Iniciação à Docência (Pibid). Fundação Carlos Chagas - Fcc, São Paulo, v. 5, n. 41, p. 1-120, 15 out. 2014. Disponível em: http://publicacoes.fcc.org.br//index.php/textosfcc/issue/view/298. Acesso em: 02 jan. 2021.

GUIMARÃES, A. M. de M. (org.). O agir educacional nas representações de professores de língua materna. In: MACHADO, A. R; GUIMARÃES, A. M. de M; COUTINHO, A. (Org.). O Interacionismo Sociodiscursivo: questões epistemológicas e metodológicas. Campinas: Mercado de Letras, 2007, p. 201-220.

MACHADO, A. R. Trabalho prescrito, planificado e realizado na formação de professores: primeiro olhar. Scripta, Belo Horizonte, v. 11, n. 6, p. 39-53, $2^{\circ}$ sem. 2002. Disponível em: http://periodicos. pucminas.br/index.php/scripta/article/view/12448. Acesso em: 02 jan. 2021.

MACHADO, A. R. Por uma concepção ampliada do trabalho do professor. In: GUIMARÃES, A. M. de M; MACHADO, A. R; COUTINHO, A. (Orgs.). O Interacionismo Sociodiscursivo: questões epistemológicas e metodológicas. Campinas: Mercado de Letras, 2007, p. 77-97.

MACHADO, A. R. ABREU-TARDELLI, L. S. Textos prescritivos da educação presencial e a distância: fonte primeira do estresse do professor? In: MACHADO, A. R; ABREU-TARDELLI, L. S; CRISTOVÃO, V. L. L. (Org.). Linguagem e Educação: o trabalho do professor em uma nova perspectiva. Campinas: Mercado de Letras, 2009, p. 101-116.

MACHADO, A. R; CRISTOVÃO, V. L. L. Representações sobre o professor e seu trabalho em proposta institucional brasileira para a formação docente. In: MACHADO, A. R; ABREU-TARDELLI, L. S; CRISTOVÃO, V. L. L. Linguagem e Educação: o trabalho do professor em uma nova perspectiva. Campinas: Mercado de Letras, 2009.

MACHADO, A. R. et al. Relações entre linguagem e trabalho educacional: novas perspectivas e métodos no quadro do interacionismo sociodiscursivo. In: MACHADO, A.R; ABREU-TARDELLI, L. S; CRISTOVÃO, V. L. L. (Org.). Linguagem e Educação: o trabalho do professor em uma nova perspectiva. Campinas: Mercado de Letras, 2009. p. 15-29. 
MACHADO, A. R. Trabalho prescrito, planificado e realizado na formação de professores: primeiro olhar. In: MACHADO, A. R.; ABREU-TARDELLI, L. S.; CRISTOVÃO, V. L. L. (Orgs.). Linguagem e educação: o trabalho do professor em uma nova perspectiva. Campinas: Mercado de Letras, $p$. 79 - 99, 2009.

MOREIRA, H; CALEFFE, L. G. Metodologia da pesquisa para o professor pesquisador. Rio de Janeiro: Lamparina, 2008.

NÓVOA, A. Firmar a posição como professor, afirmar a profissão docente. Cadernos de Pesquisa, [s.l.], v. 47, n. 166, p. 1106-1133, dez. 2017. Disponível em: http://dx.doi.org/10.1590/198053144843. Acesso em: 15 out. 2019.

SAUJAT, F. O trabalho do professor nas pesquisas em educação: um panorama. In: MACHADO, A. R. (Org.). O ensino como trabalho: uma abordagem discursiva. Campinas: Mercado de Letras, 2004, p. 3-34.

TARDIF, M. Os professores enquanto sujeitos do conhecimento: subjetividade, prática e saberes no magistério. In: CANDAU, V. M. (Org.). Didática, currículo e saberes escolares. Rio de Janeiro: Dp \& A editora, 2000.

TARDIF, M; RAYMOND, D. Saberes, tempo e aprendizagem do trabalho no magistério. Educação \& Sociedade, [S.L.], v. 21, n. 73, p. 209-244, dez. 2000. FapUNIFESP (SciELO). Disponível em: http:// dx.doi.org/10.1590/s0101-73302000000400013. Acesso em: Acesso em: 02 jan. 2021.

TARDIF, M.; LESSARD, C. 0 trabalho docente: elementos para uma teoria da docência como profissão de interações humanas. 9. ed. Petrópolis: Vozes, 2014.

\section{Sobre as autoras}

Andreia Rezende Garcia-Reis - Graduada em Letras, Mestre em Letras e Doutorado em Linguística pela Universidade Federal do Rio de Janeiro (UFRJ). Professora dos cursos de Graduação em Letras e Pedagogia; Docente do Programa de Pós-graduação em Educação da Universidade Federal de Juiz de Fora (UFJF), Faculdade de Educação. E-mail: andreiargarcia@yahoo.com.br. Lattes: http://lattes.cnpq.br/9134084821084264. OrcID: https://orcid.org/0000-0003-1209-5185.

Giovana Rabite Callian - Mestre em Educação pelo Programa de Pós-Graduação em Educação. Graduada em Pedagogia. Especialista em Ensino da Língua Portuguesa pela Universidade Federal de Juiz de Fora (UFJF). Secretaria de Estado da Educação de Minas Gerais. E-mail: giovana_callian@hotmail.com. Lattes: http://lattes.cnpq. br/0033401993608729. OrclD: https://orcid.org/0000-0001-5219-1134. 